\title{
Controversies and Pitfalls in the Diagnosis of Extrapulmonary Tuberculosis with a Focus on Genital Tuberculosis
}

\author{
Nalini Kaul Mahajan \\ Mother and Child Hospital, New Delhi, India
}

DOI: https://doi.org/10.17925/USE.2020.16.2.109

$\mathbf{E}^{\prime}$ xtrapulmonary tuberculosis (EPTB) is a complex disease; diagnosis is often difficult due to the paucibacillary status and the invasive procedures required to obtain an adequate sample. Culture testing remains the gold standard for diagnosis, but low bacterial count in EPTB may lead to a negative culture; therefore, a combination of tests is often required for confirmation of diagnosis. Microbiological tests are combined with clinical signs and symptoms, in addition to imaging techniques to improve diagnostic accuracy. Molecular tests have improved time-to-detection for disease and drug sensitivity testing; however, they cannot replace culture testing at present. Though specificity of molecular testing is high, sensitivity varies in samples from different sites, being low for TB meningitis. For genital TB, a combination of tests must be used for timely diagnosis, as disease progression leads to irreversible damage of the reproductive organs. Newer techniques, like whole genome sequencing and next-generation sequencing, are being introduced to improve diagnosis and detect drug resistance. Currently, no single diagnostic test can be considered a 'point of care' test. Early and accurate diagnosis is urgently needed to prevent the associated morbidity and mortality.

\section{Keywords}

Mycobacterium tuberculosis, tuberculosis, extrapulmonary tuberculosis, nucleic acid amplification tests, imaging, endoscopy

Disclosures: Nalini Kaul Mahajan has no financial or non-financial relationships or activities to declare in relation to this article.

Review Process: Double-blind peer review.

Compliance with ethics: This study involves a review of the literature and did not involve any studies with human or animal subjects performed by the author.

Authorship: The named author meets the International Committee of Medical Journal Editors (ICMJE) criteria for authorship of this manuscript, takes responsibility for the integrity of the work as a whole, and has given final approval for the version to be published.

Access: This article is freely accessible at touchENDOCRINOLOGY.com (c) Touch Medical Media 2020.

Received: July 4, 2020

Accepted: October 5, 2020

Published Online: December 17, 2020

Citation: US Endocrinology. 2020;16(2):109-16

Corresponding Author: Nalini Kaul Mahajan, Mother \& Child Hospital. D-59 Defence Colony, New Delhi 110024, India.

E: drnalinikaul52@gmail.com

Support: No funding was received in

the publication of this article.
Tuberculosis (TB), an infectious disease caused by Mycobacterium tuberculosis, is one the oldest infectious diseases known to man. Eradication of TB has proven to be a challenge, despite the monumental efforts of the World Health Organization (WHO). ${ }^{1}$ The emergence of multidrug-resistant and extensive drug-resistant TB, in both previously-treated and new patients, particularly in high burden areas (including India, China and the Russian Federation), has added to the problem. ${ }^{1}$ The primary site of TB infection is the lung (pulmonary TB [PTB]); from there, the bacteria can spread to any organ via the lymphatic or hematogenous routes or through contiguity. Development of primary active infection or adequate immune response, depends on a balance between host immunity and bacillary multiplication.

M. tuberculosis can persist for years within the macrophages (the body's first line of defense) by inhibiting phagosomal acidification and major histocompatibility complex class II-dependent antigen presentation. ${ }^{2}$ Reactivation of latent bacteria can occur, subsequently leading to the development of post-primary TB in approximately $10 \%$ of cases. ${ }^{3}$ Risk of progression is $5 \%$ within the first 2 years of exposure and $0.1 \%$ per year thereafter. ${ }^{3}$ Immune-system compromise remains the most important cause of reactivation, increasing the risk to $~ 50 \%$ per lifetime ${ }^{1}$. Surgical manipulation, use of immuno-suppressant drugs, high steroid levels, malnutrition, chronic illness (such as diabetes), and incomplete or inadequate anti-tubercular treatment are also associated with an increased risk of reactivation. The latter is also a major cause of multidrug-resistant (resistance to rifampicin and isoniazid) and extensive drug-resistant TB (resistance to fluoroquinolone in addition to rifampicin and isoniazid). Mutation in the bacterial genome or prodrug-activating enzymes can also lead to drug resistance. ${ }^{4}$ Worldwide, $3.4 \%$ of new TB cases and $18 \%$ of previously treated cases have shown multidrug-resistant TB or rifampicin-resistant TB, with the highest proportions (>50\%) being reported in previously treated cases. ${ }^{5}$

Though the disease is found in men, women, and children, the highest incidence is in males $\geq 15$ years of age. TB is associated with high morbidity and mortality and remains the leading cause of mortality from an infectious disease. ${ }^{1}$ It is estimated that 1.7 billion people are infected with M. tuberculosis, worldwide, and are at risk of developing post-primary disease.

This article reviews the diagnostic tests available for extrapulmonary TB (EPTB) and discusses their limitations. Since EPTB includes genital TB, the diagnostic tests will be discussed together. Tests that 
may improve diagnosis in future are also listed. A literature search was carried out using PubMed, the Cochrane library, and reports from TB-related international organizations. A selection of reports from the WHO and the European Centre for Disease Prevention were also reviewed. Search terms used were TB, latent TB, EPTB, nucleic acid amplification tests (NAATS), imaging, endoscopy, biomarkers, genomics. All relevant papers related to EPTB and genital TB were studied in detail.

\section{Extrapulmonary tuberculosis}

TB that affects any organ of the body, other than the lung parenchyma, is classified as EPTB. ${ }^{6}$ It is always secondary to the primary lung infection and may surface many years after primary exposure. It can also be found along with primary PTB. The incidence of EPTB was found to be $15 \%$ amongst the 7 million incident cases notified in 2018 (8\% in the WHO Western Pacific Region to $24 \%$ in the WHO Eastern Mediterranean Region). ${ }^{7}$ Epidemiological data suggest that children are more susceptible to EPTB.?

Common sites of EPTB are the mediastinal and cervical lymph nodes, pleura, urogenital tract, bones, abdomen, and meninges. Clinical presentation is variable, depending on the organ involved, host immune response and the degree of tissue damage that has occurred. Generally, the presenting symptoms are ambiguous, and by the time the diagnosis is made irreversible damage has occurred, since healing occurs by fibrosis. Apart from the non-specific clinical symptoms, paucibacillary status of the organism and difficulties faced in sample collection present a challenge in obtaining a speedy diagnosis. The high morbidity associated with EPTB necessitates rapid development of sensitive tests that would allow timely intervention. It is important to remember that concomitant PTB may be present and should be excluded.

\section{Genital tuberculosis}

Genital TB is generally secondary via hematogenous spread; infection through sexual contact is rare. The symptoms are mainly indistinct and by the time the condition is diagnosed, irreparable damage to the reproductive organs has occurred, leading to infertility or even sterility. Patients may also present with fever, night sweats, weight loss and acute pain.

\section{Classification of tuberculosis}

The WHO has advocated for two classifications of TB: "presumptive TB", which refers to patients with suspected TB based on presenting signs and symptoms; and "confirmed TB cases". "Confirmed TB is further categorized as "biologically confirmed", whereby a biological sample is positive for acid fast bacilli (AFB) on microscopy, culture, or molecular tests; and "clinically diagnosed," which is TB diagnosed by a clinician based on clinical evidence and suggestive histology, without bacteriological confirmation. ${ }^{6}$ EPTB cases often fall into this category, as identification of $M$. tuberculosis on smear or culture is challenging. Confirmed TB cases are further classified according to their individual features:

- anatomical site of disease: Iymph node, urogenital, bone, meningeal, abdominal, pleural, amongst others;

- history of previous treatment: treatment failure, treatment default, or TB relapse;

- drug resistance: multidrug-resistant TB or extensive drug-resistant TB; and

- human immunodeficiency virus (HIV) status - HIV positive or negative.
Table 1: Sign and symptoms in extrapulmonary tuberculosis

\begin{tabular}{|c|c|}
\hline Organ involved & Signs and symptoms \\
\hline GU (male genital) TB & $\begin{array}{l}\text { Scrotal/epididymal mass, discharging scrotal fistula, } \\
\text { urinary symptoms (sterile pyuria), odorless sterile pus, } \\
\text { testicular mass, infertility }\end{array}$ \\
\hline GU (female genital) TB & $\begin{array}{l}\text { Asymptomatic; } \\
\text { Infertility, menstrual irregularity, oligomenorrhoea/ } \\
\text { secondary amenorrhea (Asherman's syndrome), } \\
\text { lower abdominal pain, dyspareunia, TO mass, pelvic } \\
\text { inflammatory disease, persistent leucorrhoea, pyometra, } \\
\text { post-coital bleeding, postmenopausal bleeding }\end{array}$ \\
\hline Lymphatic TB & $\begin{array}{l}\text { Enlarged matted lymph nodes, sinus tract formation, } \\
\text { compression symptoms, fever, weight loss }\end{array}$ \\
\hline Pleural TB & High fever with cough, pleuritic chest pain, dyspnea \\
\hline $\begin{array}{l}\text { CNS TB (tubercular } \\
\text { meningitis) }\end{array}$ & $\begin{array}{l}\text { Persistent headache, fever, stiff neck, anorexia, vomiting, } \\
\text { photophobia, blurred consciousness, convulsions } \\
\text { (especially in children }>50 \% \text { ), coma, neurological signs; } \\
\text { hyper acute or sub-acute presentation mimicking } \\
\text { dementia }\end{array}$ \\
\hline Bone and joint TB & $\begin{array}{l}\text { Back pain (localized), functional limitation, cold abscess } \\
\text { (Pott's spine), neurological involvement }\end{array}$ \\
\hline GU (kidney) TB & $\begin{array}{l}\text { Asymptomatic/non-specific urinary symptoms, } \\
\text { hematuria, sterile pyuria, end-stage renal failure, renal } \\
\text { failure (late stages) }\end{array}$ \\
\hline GI TB & $\begin{array}{l}\text { Chronic abdominal pain, discomfort, loss of appetite, } \\
\text { change in bowel habits, nausea/vomiting, weight loss, } \\
\text { fever, night sweats }\end{array}$ \\
\hline
\end{tabular}

CNS = central nervous system; $G$ l = gastrointestinal; $G U$ = genitourinary; $T B=$ tuberculosis; $T O=$ tubo-ovarian .

\section{Diagnosis of extrapulmonary tuberculosis}

EPTB generally presents as a sub-acute or chronic illness. Diagnosis requires a very high index of suspicion due to its vague symptomatology. Apart from the plethora of investigations available, a comprehensive history and a thorough physical examination are essential for proper evaluation. A detailed history is vital to assess risk factors, for example, exposure to TB in the work or home environment, prior TB treatment, intake of immunosuppressant drugs, any chronic illness, hormonal treatment for infertility, and surgical manipulation. The patient may complain of general symptoms, such as low-grade fever, night sweats, and weight loss. Specific symptoms depend on the organ involved, for example, headache in TB meningitis, ${ }^{2}$ oligomenorrhea and infertility in genital $\mathrm{TB}_{1}{ }^{8}$ and breathing difficulty in pleural TB. ${ }^{2.9}$ Table 1 gives details of the symptoms based on the organ involved in the disease.

\section{Diagnostic criteria}

since no single test can rule out EPTB, certain diagnostic criteria have been suggested by the WHO. The use of a combined reference standard instead of culture is also recommended to improve case detection. The WHO suggests that diagnosis of EPTB should be made on the basis of any of the following criteria: one culture-positive specimen, positive histology, or strong clinical evidence consistent with active EPTB. ${ }^{10} \mathrm{~A}$ combined reference standard includes smear, culture, histopathology, cytology, biochemical analysis, response to treatment at 6 months, adenosine deaminase levels, or radiological findings - any two positive results is confirmatory. 
The lack of standardization of the criteria used in the combined reference standard remains a challenge. ${ }^{2}$

\section{Investigations}

Investigations are aimed at identification of the causative organism. The $M$. tuberculosis complex includes many Mycobacterium species. In humans, $M$. tuberculosis and $M$. africanum are responsible for $98 \%$ of infections, while $M$. bovis, accounts for $1.8 \%$ of cases. ${ }^{9}$ Both specific and non-specific tests are available for the diagnosis of $M$. tuberculosis. So far, no single test can rule out EPTB, hence the diagnostic requirement for integration of several investigations. Additionally, there are no accurate tests that can predict disease progression or relapse. ${ }^{11}$ Table 2 lists the EPTB diagnostic tests that can be used depending on the organ involved.

\section{Sample collection (tissue biopsy/aspiration of fluid)}

One of the major problems encountered in EPTB is the low number of bacilli in the sample obtained. In genital TB, cyclical endometrial shedding precludes adequate bacillary concentration in samples. An endometrial biopsy should be taken in the pre-menstrual phase, preferably from both uterine walls and fundus, to improve identification of the classic giant cells and tubercles. Detection rate can be improved by taking multiple biopsies from the involved site, concentration of fluid samples by centrifugation, and repeat testing. Taking an adequate biopsy may require guidance with ultrasound, computed tomography (CT), magnetic resonance imaging (MRI), or the use of endoscopy if the organ involved is not easily accessible. For superficial lymphadenitis, an excisional biopsy provides higher sensitivity than fine needle aspiration. ${ }^{12}$

Body fluids and tissue are collected in sterile containers under aseptic conditions. Anticoagulants may be added if fluid clotting is expected. Body fluids are typically exudates but atypical presentation is also encountered. Tissue is collected in sterile saline and transported at $4-15^{\circ} \mathrm{C}$. In the case of pleural TB, pleural wall biopsy is preferred as bacilli are concentrated there. For pleural fluid, a minimal volume of $20-50 \mathrm{~mL}$ is required. For urinary samples, three consecutive early-morning mid-stream specimens should be collected as excretion of bacteria is intermittent. Care should be taken to avoid sample contamination. ${ }^{3}$

\section{Diagnostic techniques Biological and bacteriological tests Acid-fast bacilli staining}

AFB is based on the characteristic of the lipid-rich cell wall of $M$. tuberculosis, which only stains with acid-fast stains. The original staining technique by the Ziehl-Neelsen method uses carbol-fuchsin stain. Fluorochrome staining is done using auramine or auramine-rhodamine, and has an increased sensitivity. The WHO recommends the use of light-emitting diode (LED) microscopy, since it is three times faster than conventional fluorescence microscopy. A major limitation of AFB staining is its poor sensitivity (25-75\% compared to culture), poor predictive value, the high bacterial count required to get a positive result $\left(5 \times 10^{3}-10^{4}\right.$ bacilli/ml of fluid or tissue), and an inability to identify $M$. tuberculosis species and bacterial viability. ${ }^{3}$ Paucibacillary status of EPTB further lowers the sensitivity of the test. Administration of fluoroquinolones may result in false negative results. ${ }^{2}$

\section{Histopathology}

The typical tubercular granuloma seen on histopathology has a central area of caseation surrounded by $\mathrm{T}$ and B lymphocytes, epithelioid cells, macrophages, Langhans giant cells, and fibroblasts. For genital TB, the ideal time for endometrial biopsy is the late secretory phase of the menstrual cycle. Pregnancy should be ruled out before taking an endometrial biopsy. The correlation of diagnostic criteria and histopathological examination results by bivariate analysis reveal a sensitivity and specificity of $10.7 \%$ and $100 \%$, respectively..$^{13}$ Limitations of the test include the presence of similar lesions in conditions like leprosy, systemic lupus erythematous, rheumatoid arthritis, pneumoconiosis, sarcoidosis, fungal infections, and syphilis; which results in a low sensitivity. ${ }^{14}$ Non-caseating granulomas may be formed in some organs and bacteriologically mute lesions may also be present.

\section{Tissue culture}

Bacteriological culture remains the gold standard for laboratory confirmation of $M$. tuberculosis. M. tuberculosis is a slow growing bacterium, taking approximately 2-6 weeks for growth and requires a concentration of 10-100 bacilli/mL. The traditional Lowenstein-Jensen egg-based solid culture method has been replaced by the automated rapid liquid culture system, which has shortened time to diagnosis from 4-6 weeks to 2 weeks.

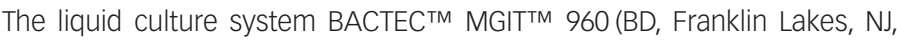
USA; mycobacteria growth indicator tube) uses modified a Middlebrook 7H9 Broth with an oxygen-sensitive fluorescent technology. It senses oxygen reduction in the culture media, media is then centrifuged and stained with a Ziehl-Neelsen stain to identify $M$. tuberculosis. The minimum time to positivity is 10-12 days; however, the culture dish is observed for a full 6-8 weeks before a final negative report is given.

Liquid culture has the advantage of increased sensitivity, Mycobacterium species identification, phenotypic drug susceptibility testing, and further genotyping for molecular epidemiology studies and mutation-based genotypic resistance testing. ${ }^{4,7,15}$ The main disadvantage of culture tests is the time required for diagnosis and paucibacillary status of EPTB, which limits the pick-up rate. ${ }^{16}$ Contamination and inhibition of growth due to bacteriostatic substances and blood are other disadvantages. Drug susceptibility testing should be done immediately once the culture is positive. ${ }^{17}$

An overall sensitivity of $65 \%$ and specificity of $100 \%$ is reported for AFB culture. ${ }^{12}$ Culture sensitivity is low for all forms of EPTB and may also vary in different forms of EPTB. ${ }^{7}$ For genital TB, pre-menstrual endometrial biopsy samples reveal a sensitivity of 30\% and $80-90 \%$ and a positivity of 1.83 and $8.8 \%$ in Lowenstein-Jensen and BACTEC media, respectively. ${ }^{18,16}$ Though culture is considered the best reference standard for TB, use of a combined reference standard improves diagnostic accuracy.

\section{Microscopic observation drug susceptibility liquid culture}

The microscopic observation drug susceptibility (MODS) assay is a liquid culture assay for TB that includes direct drug susceptibility. The cording formation specific to $M$. tuberculosis is observed microscopically. The need for subculture is circumvented by the incorporation of rifampicin and isoniazid in the initial stage of culture. It is cheap and easy to perform, making it valuable in low-resource high-burden countries. The WHO has approved MODS for drug susceptibility screening for multidrug-resistant TB. ${ }^{19}$

\section{Nucleic acid amplification tests}

NAATs involve amplification of DNA and RNA segments, to identify the microorganism in a specimen. For TB, the most commonly used 
Table 2: Investigations for extrapulmonary tuberculosis

\begin{tabular}{|c|c|c|c|c|}
\hline \multirow[t]{2}{*}{ Organ involved } & \multicolumn{4}{|c|}{ Investigation } \\
\hline & Biological & Imaging & Endoscopy & Biomarker \\
\hline $\begin{array}{l}\text { GU (male } \\
\text { genital) TB }\end{array}$ & $\begin{array}{l}\text { Sample: discharge } \\
\text { AFB stain, culture, PCR; } \\
\text { HPE: necrotizing epithelioid cell } \\
\text { granulomas }\end{array}$ & $\begin{array}{l}\text { USG: Scrotal/epididymal mass, hypoechoic } \\
\text { epididymis, scrotal fistula }\end{array}$ & NA & \\
\hline $\begin{array}{l}\text { GU (female } \\
\text { genital) TB }\end{array}$ & $\begin{array}{l}\text { Sample: EB, laparoscopic/ } \\
\text { hysteroscopic targeted tissue } \\
\text { biopsy; } \\
\text { Microscopy, culture, PCR }\end{array}$ & $\begin{array}{l}\text { USG: thin ill-defined endometrium, } \\
\text { endometrial fluid, calcifications, intrauterine } \\
\text { synechiae, hydrosalpinx, free or loculated } \\
\text { pelvic fluid, TO mass; } \\
\text { HSG: beaded tubes, hydrosalpinx, filling } \\
\text { defect and narrowing of uterine cavity } \\
\text { (should not be performed for diagnosis of } \\
\text { GTB or during active pelvic infection); } \\
\text { CT scan: adnexal mass mixed (solid and } \\
\text { cystic) with multilocular caseous necrotic } \\
\text { enhancement, high density ascites, thickened } \\
\text { and enhanced peritoneum, lymphadenopathy }\end{array}$ & $\begin{array}{l}\text { Laparoscopy: Pelvis_-adhesions, frozen } \\
\text { pelvis, straw-colored fluid in pouch of Douglas, } \\
\text { peritoneal tubercles; } \\
\text { Fallopian tubes_-showing hydrosalpinx, cornual } \\
\text { block, beading, rigid tubes, fimbrial phimosis, } \\
\text { TO mass; } \\
\text { Uterus—-may have surface tubercles and show } \\
\text { intravasation of dye injected to test for patency; } \\
\text { Hysteroscopy: Bald/unhealthy endometrium, } \\
\text { caseation, calcification, adhesions mild to } \\
\text { severe, shrunken cavity, periosteal fibrosis, poor } \\
\text { distensibility }\end{array}$ & \\
\hline Lymphatic TB & $\begin{array}{l}\text { Sample: pus, FNA specimen or } \\
\text { excisional biopsy; } \\
\text { AFB stain, culture } \\
\text { HPE: granuloma with or } \\
\text { without caseation/calcification }\end{array}$ & $\begin{array}{l}\text { USG: hypoechoic cystic lesions with thick } \\
\text { capsule; } \\
\text { CT: conglomerate nodal masses, } \\
\text { central lucency, irregular rim of contrast } \\
\text { enhancement, surrounding inflammation; } \\
\text { MRI: discrete or matted masses with or } \\
\text { without necrotic foci, soft tissue edema }\end{array}$ & NA & \\
\hline Pleural TB & $\begin{array}{l}\text { Sample: pleural fluid, biopsy, } \\
\text { induced sputum; } \\
\text { Culture, histology, DNA-PCR }\end{array}$ & $\begin{array}{l}\text { CT scan: pleural thickening; } \\
\text { CXR: pleural effusion }\end{array}$ & NA & $\begin{array}{l}\text { ADA in pleural } \\
\text { fluid: suggestive } \\
\text { if }>40 \mathrm{U} / \mathrm{l}\end{array}$ \\
\hline $\begin{array}{l}\text { CNS TB } \\
\text { (tubercular } \\
\text { meningitis) }\end{array}$ & $\begin{array}{l}\text { Sample: CSF; } \\
\text { >lymphocytes, } \\
\text { plasma-glucose ratio }<50 \% \text {; } \\
\text { Culture, DNA-PCR }\end{array}$ & $\begin{array}{l}\text { Head CT with contrast: hydrocephalus, } \\
\text { basal contrast enhancing, infarction; } \\
\text { MRI: high-definition infratentorial lesions and } \\
\text { early changes }\end{array}$ & NA & \\
\hline GU (kidney) TB & $\begin{array}{l}\text { Sample: urine, renal biopsy; } \\
\text { Urine analysis: hematuria, } \\
\text { proteinuria, sterile pyuria; } \\
\text { Culture of three early-morning } \\
\text { urine samples, DNA-PCR; } \\
\text { HPE: small bilateral cortical } \\
\text { necrosis/granulomatous } \\
\text { destruction of renal tissue/ } \\
\text { interstitial nephritis; } \\
\text { Ureter, bladder: strictures, } \\
\text { fibrosis }\end{array}$ & $\begin{array}{l}\text { CT scan: calcifications, strictures, thickening, } \\
\text { fibrosis, and ulceration; } \\
\text { Intravenous urography: distortion of } \\
\text { calyces, ureteral stricture, bladder fibrosis }\end{array}$ & $\begin{array}{l}\text { Cystourethroscopy and ureteroscopy for the } \\
\text { detection of ulcers, growth, and fibrosis }\end{array}$ & \\
\hline GI TB & $\begin{array}{l}\text { Sample: peritoneal fluid, tissue } \\
\text { biopsy; } \\
\text { AFB stain, DNA-PCR, culture }\end{array}$ & $\begin{array}{l}\text { USG/CT: asymmetric thickening of the bowel } \\
\text { wall (especially ileocecal region), abdomen } \\
\text { lymphadenopathy with or without ascites (CT } \\
\text { better for LN calcifications) }\end{array}$ & $\begin{array}{l}\text { Endoscopy (for suspected GI TB): } \\
\text { >segmental lesions helpful in performing } \\
\text { targeted biopsies }\end{array}$ & \\
\hline
\end{tabular}

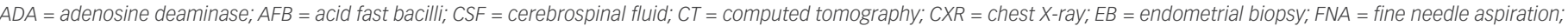
$\mathrm{GI}$ = gastrointestinal; $\mathrm{GU}=$ genitourinary; $H P E=$ histopathological examination; $H S G=$ hysterosalpingography; $L N=l y m p h$ node; $M R I=m a g n e t i c$ resonance imaging; $N A=$ not applicable; $P C R=$ polymerase chain reaction; TB = tuberculosis; TO = tubo-ovarian; USG = ultrasonography. 
target sequences are IS6110 and a 16SRNA, which are specific to the $M$. tuberculosis complex. ${ }^{20}$ Molecular genetic tests have been approved by the WHO for the diagnosis of PTB and EPTB, as they have a quick turn-around time (48-72 hours), can detect low bacterial count (10 mycobacteria) in the specimen, ${ }^{21}$ and allow for rapid initiation of drug susceptibility testing. Test sensitivity and specificity, calculated from pooled data, was $84.9 \%$ and $92.5 \%$ for lymph nodes, $83.8 \%$ and $98.1 \%$ for gastric fluid, $81.2 \%$ and $98.1 \%$ for tissue, and $79.5 \%$ and $98.6 \%$ for cerebrospinal fluid, respectively. 2,6 The sensitivity is highly variable between samples and a negative test may not exclude the diagnosis.22 NAATs currently used for the diagnosis of TB are polymerase chain reaction (PCR), real-time PCR, and loop-mediated isothermal amplification (LAMP).,23

Single tube nested reverse transcription PCR detects the live organism in the specimen. A major drawback of this test is that the sample needs to be transported to the laboratory in ice within 2 hours to prevent degradation of RNA; the average half-life of bacterial mRNA is 3 minutes.

DNA-PCR tests, both commercially-available and laboratory-developed, are available. Commercial tests require sophisticated technology and are expensive. To mitigate the cost issues, many laboratories have developed in-house DNA-PCR tests. As with all tests used to diagnose TB, the WHO mandates validation of these tests.

There are several commercial DNA-PCR tests available. The COBAS ${ }^{\circledR}$ Amplicor (Roche Diagnostic Systems, Basel, Switzerland) amplifies a portion of the 16SrRNA gene containing a sequence that hybridizes with an oligonucleotide probe specific for $M$. tuberculosis complex bacteria. The Amplified Mycobacterium Tuberculosis Direct Test (Gen-Probe, San Diego, CA, USA) is only approved for smear-positive specimens, while the enhanced Amplified Mycobacterium Tuberculosis Direct Test (GenProbe) is approved for both smear-negative and -positive cases, showing a sensitivity close to $100 \%$. The COBAS ${ }^{\circledast}$ TaqMan $^{\circledR}$ (Roche Diagnostic Systems) M. tuberculosis assay is widely used. It has demonstrated a $96 \%$ sensitivity and $74 \%$ specificity in smear-positive cases. ${ }^{20}$ However, sensitivity and specificity decreased to $64 \%$ and $99.3 \%$, respectively, in smear-negative cases. Diagnostic accuracy is better for pulmonary cases. The Xpert ${ }^{\circledR}$ MTB/RIF assay (Cepheid, Sunnyvale, CA, USA) is a cartridge-based, semiautomated, real-time quantitative PCR assay for amplifying M. tuberculosis DNA and part of the rpoB gene encoding rifampicin resistance. Automation reduces the risk of contamination. An advanced version, Xpert ${ }^{\circledR}$ MTB/RIF Ultra, has been introduced recently.

Line probe assays are NAATs that are used to detect common genomic mutations responsible for drug resistance from a biological probe or culture by DNA hybridization. Examples include the GenoType ${ }^{\circledR}$ MTBDR assay (Hain Lifescience, Nehren, Germany) and the INNO-LiPA ${ }^{\circledR}$ Rif.TB kit (Innogenetics, Ghent, Belgium) ${ }^{24}$

The NAATs approved for use by the WHO in 2010 were the Genexpert MTB/RIF assay (Cepheid Inc, Sunnyvale, CA, USA) and line probe assays, which permit mycobacterium identification and testing of drug resistance simultaneously. ${ }^{23}$ The line probe assay detects $M$. tuberculosis and rifampicin- or isoniazid-resistant mutations, with a sensitivity of 58-80\%. GeneXpert MTB/RIF assay (Cepheid Inc, Sunnyvale, CA, USA) is recommended over conventional tests for diagnosis of EPTB by the WHO, since the detection rate is $2-3$ times higher than conventional tests. Use of these tests is challenging in resource-limited settings; however, cheaper alternatives that have been developed have yet to be validated.

A systemic review and meta-analysis by Denkinger et al. included 18 studies and 4,461 extrapulmonary samples (tuberculous meningitis, pleural, lymph node, bone or joint, genitourinary, peritoneal, pericardial, and disseminated TB). ${ }^{25}$ Xpert MTB/RIF pooled specificity was consistently $>98.7 \%$ against the combined reference standard across different sample types. A recent analysis of 66 studies evaluating 16,213 specimens for the detection of EPTB and rifampicin resistance determined a pooled Xpert MTB/RIF sensitivity (defined by culture) from $31 \%$ in pleural tissue to $97 \%$ in bone or joint fluid (moderate-certainty evidence). ${ }^{7}$ A higher sensitivity, of more than $80 \%$, was seen in urine, joint fluid, bone, and tissue. Less variation was seen in Xpert MTB/RIF specificity, being $\geq 98 \%$ in cerebrospinal fluid, pleural fluid, urine, and peritoneal fluid. Regarding rifampicin resistance, a pooled sensitivity of 95.0\% (89.7-97.9\%; 20 studies, 148 specimens) and a specificity of 98.7\% (97.8-99.4\%; 39 studies, 1,088 specimens) was observed with high-certainty evidence.?

The Xpert MTB/RIF Ultra was endorsed by the WHO in 2017 as a substitute for the Xpert MTB/RIF. ${ }^{23}$ It has an improved sensitivity, particularly in paucibacillary samples; however, the specificity is lower. The detection of drug resistance (95\%) is similar in both tests. ${ }^{26} \mathrm{An}$ increased sensitivity of $70 \%$ (95\% confidence interval [Cl] 47-87) is observed for the detection of TB meningitis compared with the Xpert MTB/RIF (43\%, [95\% Cl 23-66]) and standard AFB culture test (43\% [95\% $\mathrm{Cl} 23-66])_{r^{12,23}}$ however, additional tests are important to avoid missing the diagnosis.

A major drawback of NAATs is the inability to differentiate between viable and non-viable organisms, hence the test can remain positive for long periods in patients who are taking anti-TB medications or who have completed TB treatment. Contamination may lead to a false-positive test, while false negatives may result from poor extraction of DNA due to Iow mycobacterial count or PCR inhibitors. ${ }^{27}$ False-positive results may also be obtained because of $M$. tuberculosis DNA, which remains in tissues after eradication of live bacteria. Discrepancy between the results of culture tests and PCR have been reported in genital TB with PCR negative samples being positive on culture testing. ${ }^{18} \mathrm{~A}$ combination of tests is advised to improve diagnostic accuracy. Even in the diagnosis of PTB, a NAAT should be performed in conjunction with an AFB smear and culture test. Though Xpert MTB/RIF is an important technological breakthrough in the diagnostic armamentarium of TB, it still falls short of being the point-of-care test. ${ }^{28}$

LAMP is an isothermal nucleic acid amplification technique. A constant temperature is used for amplification of a few copies of target DNA, instead of a thermal cycler. While LAMP offers speed and specificity and is also cost-effective, the risk of aerosol contamination remains; however, it could prove useful in low-resource settings. The WHO recommended LAMP for the diagnosis of PTB in 2016. For EPTB a good sensitivity of $95.6 \%$ is seen compared to the three conventional methods: liquid culture $69.6 \%$, solid culture $65.2 \%$, and smear microscopy $17.4 \% .{ }^{29}$ LAMP requires evaluation in children and HIV cases. $^{30}$

Next-generation NAATs have been developed to minimize cost and increase portability. Three rapid tests have been launched using microarray technology (VereMTB ${ }^{\text {TM }}$ assay; Veredus Laboratories, Singapore),

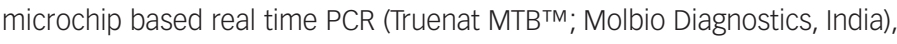


and isothermal DNA amplification (EasyNAT ${ }^{\circledast}$ TB Diagnostic Kit; Ustar Biotechnologies, China). The preliminary steps of sample handling and DNA extraction technique remain unchanged. These tests have only been used for sputum samples, their role in EPTB has not been tested. In addition, they have not yet been validated by the WHO. ${ }^{31}$

\section{Whole genome sequencing}

Whole genome sequencing can identify almost the entire genome of M. tuberculosis. ${ }^{32}$ The test is performed on $M$. tuberculosis isolates from the culture, and identifies the organism in 1-3 days. A standardized protocol allows comparison of genotypes from laboratories around the world. ${ }^{33}$ It is beneficial in tracking $M$. tuberculosis outbreaks, differentiating re-infection and relapse, and identifying laboratory cross-contamination. ${ }^{34}$

\section{Next-generation sequencing}

Next-generation sequencing provides detailed sequence information for multiple gene regions or whole genomes of interest, ${ }^{32}$ which is beneficial for drug susceptibility testing. Next-generation sequencing and analysis of the whole genome may become the reference standard for drug resistance in the future. Currently, cost limitations and technical requirements prevent its widespread use.

\section{Immunological tests}

The tuberculin skin test and interferon-gamma release assays (IGRAS) are used to diagnose latent TB infection. These tests detect an immune response to mycobacterial antigens, and consequently, do not allow a direct measure of persistent infection. ${ }^{3}$ They cannot differentiate between active and latent disease.

\section{Tuberculin skin test/Mantoux test}

A tuberculin skin test is performed by injecting $0.1 \mathrm{~mL}$ of tuberculin purified protein derivative into the inner surface of the forearm intra-dermally, and skin reaction is read after $48-72$ hrs. A positive test (reaction $>10 \mathrm{~mm}$ ) is an important indicator of $M$. tuberculosis infection. The tuberculin skin test has a low specificity in BCG (Bacillus Calmette-Guérin)-vaccinated populations..$^{35}$ False positives may occur in infection with non-TB mycobacteria or previous BCG vaccination. False negatives may be seen in overwhelming TB infection, recent TB, and in immunocompromised states. ${ }^{1,3,35}$ This test has limited value in high-burden countries.

\section{Interferon-gamma release assays}

IGRAs measure interferon-gamma (IFN- $\gamma$ ) release in response to $M$. tuberculosis-specific antigens encoded within the region of difference ESAT-6 (early secretory antigenic target-6), CFP-10 (culture filtrate protein 10), and the TB7.7. This portion of the M. tuberculosis genome is absent in BCG strains and most nontuberculous mycobacteria species. ${ }^{12}$ Two commercial IGRAs are available: the QuantiFERON ${ }^{\circledR}$-TB Gold In-Tube assay (Qiagen, Hilden, Germany) and the T-SPOT ${ }^{\oplus}$.TB (Oxford Immunotec, Oxfordshire, UK). Repeat testing is required for indeterminate results, which could reflect technical factors (e.g., inappropriate storage of blood) or an impaired immune response. IGRAs cannot replace microbiological methods for diagnosis; however, they are ideal for serial testing and can be repeated without sensitization and boosting. ${ }^{36}$ Though, detection of immune response is not dependent on mycobacterial concentration in the sample, it is not of value in EPTB and provides only supplementary information. A negative IGRA does not rule out active TB. Specificity is $99.4 \%(95 \% \mathrm{Cl}$
97.9-99.9\%) and is unaffected by BCG vaccination. Sensitivity may be lowered in immunocompromised conditions, advanced disease, and malnutrition. The European Centre for Disease Prevention and Control guidance document states that the "high negative predictive value (NPV) for progression of IGRAs indicates that at the time of testing and in the context of an overall risk assessment, progression to active TB in healthy immunocompetent individuals with negative IGRAs is very unlikely in the next 2 years". ${ }^{37}$

\section{Imaging techniques}

Chest $\mathrm{X}$-ray is an important screening tool for the primary focus in TB or associated PTB in EPTB cases. Old healed or active infection is present in $10-50 \%$ of urogenital TB cases; ${ }^{38}$ old healed infection may present as calcification in the organ or lymph nodes, which is visible via chest X-ray.

CT is the modality of choice for lymphadenopathy and abdominal TB, whilst MRI is indicated in TB of CNS, musculo-skeletal system, in pregnant women, and children. CT scans and MRI visualize multi-locular caseous necrotic enhancement in the affected organ, lymph nodes, high density ascites/pleural effusion, and thickened and enhanced peritoneum/pleura, with increased sensitivity. Features observed depend on disease stage. MRI provides better soft-tissue resolution and contrast enhanced MRIs are useful in defining focal tissue edema and focal hypoperfusion. ${ }^{9}$

${ }^{18} \mathrm{~F}-$ fluorodeoxyglucose positron emission tomography $\left({ }^{18} \mathrm{~F}-\mathrm{FDG}-\mathrm{PET}\right)$ is helpful in monitoring response and determining the extent of disease. ${ }^{39}$ An ${ }^{18} \mathrm{~F}-\mathrm{FDG}-\mathrm{PET}$ scan, with or without $\mathrm{CT}$, is very sensitive in the early detection of TB in most parts of the body. It aids in selecting appropriate site for biopsy, staging infection, detection of disease in previously unknown sites (EPTB), and monitoring response to therapy. Its major limitation is its inability to differentiate TB from malignancy. ${ }^{40}$

Hysterosalpingography is not diagnostic but may reveal abnormalities suggestive of genital TB, such as hydrosalpinx, beaded tubes, intra-uterine adhesions, or a shrunken endometrial cavity. It is contraindicated in the presence of recent acute pelvic infection. High-resolution ultrasonography may demonstrate features suggestive of $M$. tuberculosis infection in the organ involved. The degree of calcification and caseation is responsible for variation in echotexture. Endoscopy remains the gold standard for the evaluation of pelvic infection. It is useful in localization and diagnosis of tubercular lesions, and to obtain a well targeted tissue biopsy for TB testing. Further details of imaging investigations are provided in Table 2.

\section{Biomarkers in body fluids}

Adenosine deaminase activity is increased in patients with TB due to T-cell stimulation, which occurs in response to the mycobacterium. It has been proposed as a surrogate marker in pleural, pericardial, and peritoneal fluid. ${ }^{41}$ Both false-negative and false-positive results are high, and currently it is not advocated or available for routine use. ${ }^{41,17}$ IFN- $\gamma$ estimation in pleural and pericardial fluid has been studied for early diagnosis; a sensitivity of $89 \%$ and a specificity of $97 \%$ in pleural fluid has been reported in a meta-analysis. ${ }^{42}$

Lipoarabinomannan (LAM) is a component of the M. tuberculosis cell wall and is detected in the urine of patients with active TB. The Alere Determine ${ }^{\mathrm{TM}}$ TB LAM Ag test (Alere, Waltham, MA, USA) is an immunochromatographic 
assay. The WHO recommends its use to assist in the diagnosis of HIV-associated TB with CD4+ lymphocyte counts $<100$ cells/ $\mu$ l, and in those who are seriously ill, irrespective of cell count?

Genome-wide transcriptional biosignature detection in whole blood looks promising.

\section{The future of diagnostic techniques}

Newer techniques are under consideration to improve the diagnosis of PTB and EPTB. These include application of nanotechnology, microfluidics and TB metabolites in the breath. Host-response biomarkers, antigen detection technology, and the use of proteomics and transcriptomics to detect progression to active disease, are under research and may improve the detection and management of EPTB in the future. ${ }^{11}$ Validation of these technologies is required before they are available for commercial use. The ideal test must provide both high sensitivity and specificity, which is difficult to achieve. Target product profiles set by the WHO (2014) propose a specificity of $98 \%$ for a diagnostic test, but a minimum of $70 \%$ if follow-up confirmatory tests are carried out. ${ }^{43}$

\section{Genital TB}

In female genital TB, the fallopian tubes are affected in $90 \%$ patients, followed by the endometrium (50-60\%) and ovaries (10-30\%). ${ }^{44}$ Cervical involvement is seen in $5-15 \%$ of patients, vaginal and vulval disease is rare, only seen in about $1 \%{ }^{44}$ The most common presenting features are infertility and menstrual irregularity. Patients may also present with complaints of persistent vaginal discharge, post-coital bleeding, lower abdominal discomfort, dyspareunia, pelvic inflammatory disease and Bartholin's abscess. ${ }^{44}$

Investigations for female genital TB are similar to other forms of EPTB and are listed in Table 2. Endoscopy is the gold standard for pelvic examination. A combined reference standard is also helpful for detection. Evaluation of the Gene XPERT for EPTB, including genital TB, was carried out by Sharma et al. ${ }^{45}$ The study included 95 endometrial samples from participants who were either treatment naive or were on anti-TB treatment for $<2$ weeks. Samples were subjected to Ziehl-Neelsen staining, Xpert MTB/RIF assay, and culture on both BACTEC and Lowenstein-Jensen media. The overall sensitivity and specificity of Xpert MTB/RIF assay with culture were $71 \%$ and $95 \%$, respectively; sensitivity increased from 50\% to $91 \%$ with increasing conventional diagnostic parameters (of the combined reference standard) taken as positive. For endometrial samples, the specificity was 100\%, sensitivity $33 \%$, positive predictive value $100 \%$, and negative predictive value $96 \%$. The addition of the combined reference standard improved sensitivity to $50 \%$. Conventional methods of diagnosis, such as microscopy and culture, have been shown to be less sensitive when compared with PCR. Reports of endometrial biopsy samples negative on DNA PCR but positive on culture, ${ }^{18,46}$ underpin the importance of using both tests for diagnosis. Early treatment of female genital TB is important as fertility rates do not improve, despite treatment, once scarring of the fallopian tubes or uterus has occurred.

Male genital TB is rare and usually occurs due to descending infection from kidneys or direct extension from a neighboring focus. The epididymis and the prostate are most commonly affected, while testicular TB is uncommon. ${ }^{2,47}$ Presenting symptoms may be acute (epididymitis or epididymo-orchitis) or chronic (chronic prostatitis). Infertility results from ejaculatory-duct obstruction or damage to epididymis and vas deferens. ${ }^{2}$ Investigations are detailed in Table 2.

\section{Conclusion}

EPTB is a complex disease; diagnosis is difficult due to the paucibacillary status and invasive procedures required to obtain an adequate sample in many cases. Since no single diagnostic test can be considered a point of care test, microbiological tests need to be combined with clinical signs and symptoms and imaging techniques to improve diagnostic accuracy. Although molecular tests (Gene Xpert and Gene Xpert Ultra) have improved time to detection of disease and drug sensitivity, they cannot replace the gold-standard culture technique, at present. Though the specificity of molecular tests is high, sensitivity varies between samples from different sites. For TB meningitis, clinical judgement is advised if gene Xpert is negative. The same applies to infertile patients suspected with genital $T B$, as disease progression leads to irreversible damage. A combined reference standard is often used for TB evaluation as culture reference alone is inadequate. Early and accurate diagnosis is needed to prevent the associated morbidity and mortality. $]$
1. World Health Organization, Global Tuberculosis Report 2019. Available at: www.who.int/teams/ global-tuberculosis-programme/global-report-2019 (accessed October 21, 2020).

2. Norbis L, Alagna R, Tortoli E, et al. Challenges and perspectives in the diagnosis of extrapulmonary tuberculosis. Expert Rev Anti Infect Ther. 2014:12:633-7.

3. European Centre for Disease Prevention and Control, ECDC TECHNICAL REPORT Handbook on tuberculosis laboratory diagnostic methods in the European Union Updated 2018, 2018. Available at: www.ecdc.europa.eu/en/publications-data/ handbook-tuberculosis-laboratory-diagnostic-methods-europeanunion-updated-2018 (accessed October 21, 2020).

4. Kurz SG, Furin JJ, Bark CM. Drug-resistant tuberculosis: challenges and progress. Infect Dis Clin North Am. 2016;30:509-22.

5. Seung KJ, Keshavjee S, Rich ML. Multidrug-resistant tuberculosis and extensively drug-resistant tuberculosis. Cold Spring Harb Perspect Med. 2015;5:a017863.

6. World Health Organization, Definitions and reporting framework for tuberculosis - 2013 revision (updated December 2014 and January 2020). Available at: http://apps.who.int/iris/ bitstream/10665/79199/1/9789241505345_eng.pdf (accessed October 21, 2020).

7. Kohli M, Schiller I, Dendukuri $\mathrm{N}$, et al. Xpert ${ }^{\circledR}$ MTB/RIF assay for extrapulmonary tuberculosis and rifampicin resistance. Cochrane Database Syst Rev. 2018;8:CD012768.

8. Arora R, Sharma JB. Female genital tuberculosis - a diagnostic and therapeutic challenge. Indian J Tuberc. 2014;61:98-2.

9. Muneer A, Macrae B, Krishnamoorthy S, Zumla A. Urogenita tuberculosis - epidemiology, pathogenesis and clinical features. Nat Rev Urol. 2019;16:573-98.

10. World Health Organization, Global Tuberculosis Report 2020 Available at: www.who.int/tb/publications/global_report/en/ index.html (accessed October 21, 2020).

11. Walzl G, McNerney R, du Plessis N, et al. Tuberculosis: advances and challenges in development of new diagnostics and biomarkers. Lancet Infect Dis. 2018;18:e199-210.

12. Fontanilla JM, Barnes A, von Reyn CF. Current diagnosis and management of peripheral tuberculous lymphadenitis Clin Infect Dis. 2011;53:555-62

13. Mondal SK. Histopathologic analysis of female genital tuberculosis: a fifteen-year retrospective study of 110 cases in eastern India. Turk Patoloji Derg. 2013;29:41-5.

14. Ligthelm L, Nicol MP, Hoek KG, et al. Xpert MTB/RIF for rapid diagnosis of tuberculous lymphadenitis from fine-needle-aspiration biopsy specimens. I Clin Microbio. 2011:49:3967-70

15. World Health Organization, Policy statement: liquid media for culture and DST, 2007. Available at: www.who.int/tb/laboratory/ policy_liquid_medium_for_culture_dst/en/ (accessed October 21, 2020).

16. Goel G, Khatuja R, Radhakrishnan G, et al. Role of newer methods of diagnosing genital tuberculosis in infertile women. Indian J Pathol Microbiol. 2013;56:155-7.

17. Lee JY. Diagnosis and treatment of extrapulmonary tuberculosis. Tuberc Respir Dis (Seoul). 2015;78:47-55

18. Shrivastava G, Bajpai T, Bhatambare GS, Patel KB. Genital tuberculosis: comparative study of the diagnostic modalities.
J Hum Reprod Sci. 2014:7:30-3.

19. Lora MH, Reimer-McAtee MJ, Gilman RH, et al. Evaluation of microscopic observation drug susceptibility (MODS) and the string test for rapid diagnosis of pulmonary tuberculosis in HIV/AIDS patients in Bolivia. BMC Infect Dis. 2015;15:222.

20. Wang H-Y, Lu J-J, Chang C-Y, et al. Development of a high sensitivity TaqMan-based PCR assay for the specific detection of Mycobacterium tuberculosis complex in both pulmonary and of Mycobacterium tuberculosis complex in both pulmonary

21. Manjunath N, Shankar P, Rajan L, et al. Evaluation of a polymerase chain reaction for the diagnosis of tuberculosis. Tubercle. 1991;72:21-7.

22. Dinnes J, Deeks J, Kunst H, et al. A systematic review of rapid diagnostic tests for the detection of tuberculosis infection. Health Technol Assess. 2007:11:1-196.

23. World Health Organization, WHO meeting report of a technical expert consultation: non-inferiority analysis of Xpert MTF/ RIF Ultra compared to Xpert MTB/RIF, 2017. Available at: https://apps.who.int/iris/bitstream/handle/10665/254792/ WHO-HTM-TB-2017.04-eng.pdf? sequence $=1$ (accessed October 21, 2020)

24. Lange C, Mori T. Advances in the diagnosis of tuberculosis. Respirology. 2010;15:220-40.

25. Denkinger CM, Schumacher SG, Boehme CC, et al. Xpert MTB/RIF assay for the diagnosis of extrapulmonary tuberculosis: a systematic review and meta-analysis. Eur Respir $\mathrm{J}$ 2014;44:435-6

26. Dorman SE, Schumacher SG, Alland D, et al. Xpert MTB/RIF Ultra for detection of Mycobacterium tuberculosis and rifampicin 
resistance: a prospective multicentre diagnostic accuracy study. Lancet Infect Dis. 2017;18:76-84

27. Zakham F, Bazoui H, Akrim M, et al. Evaluation of conventional molecular diagnosis of Mycobacterium tuberculosis in clinical specimens from Morocco. I Infect Dev Ctries. 2012;6:40-5.

28. Weyer K, Carai S, Nunn P. Viewpoint TB diagnostics: what does the world really need? I Infect Dis. 2011;204(Suppl 4):S1196-202.

29. Ghosh PK, Chakraborty B, Maiti PK, Ray R. Comparative evaluation of loop-mediated isothermal amplification and conventional methods to diagnose extrapulmonary tuberculosis. Ann Trop Med Public Health. 2017;10:160-4.

30. Eddabra R, Ait Benhassou H. Rapid molecular assays for detection of tuberculosis Pneumonia (Nathan) 2018:10:4.

31. MCNerney R, Cunningham J, Hepple P, Zumla A. New tuberculosis diagnostics and rollout. Int J Infect Dis. 2015;32:81-6.

32. Doyle RM, Burgess C, Williams R, et al. Direct whole-genome sequencing of sputum accurately identifies drug-resistant Mycobacterium tuberculosis faster than MGIT culture sequencing. J Clin Microbiol. 2018;56:e00666-18.

33. van Embden J, Cave MD, Crawford JT, et al. Strain identification of Mycobacterium tuberculosis by DNA fingerprinting: recommendations for a standardized methodology. J Clin Microbiol. 1993:31:406-9.
34. Haas CT, Roe JK, Pollara G, et al. Diagnostic 'omics' for active tuberculosis. BMC Med. 2016;14:37.

35. Pai M, Zwerling A, Menzies D. Systematic review: T-cell-based assays for the diagnosis of latent tuberculosis infection: an update. Ann Intern Med 2008:149:177-4.

36. Pai M, Joshi R, Bandyopadhyay $M$, et al. Sensitivity of a whole-blood interferon-gamma assay among patients with pulmonary tuberculosis and variations in T-cell responses during anti-tuberculosis treatment. Infection. 2007;35:98-3.

37. European Centre for Disease Prevention and Control, Public health guidance on screening and vaccination for infectious diseases in newly arrived migrants within the EU/EEA, 2018. Available at: www.ecdc.europa.eu/en/publications-data/publichealth-guidance-screening-and-vaccination-infectious-diseasesnewly (accessed October 21, 2020)

38. Merchant S, Bharati A, Merchant N. Tuberculosis of the genitourinary system-Urinary tract tuberculosis: renal tuberculosis-Part I. Indian J Radiol Imaging. 2013;23:46-63.

39. Gambhir S, Ravina M, Rangan K, et al. Imaging in extrapulmonary tuberculosis. Int I Infect Dis. 2017;56:237-47.

40. Yu WY, Lu PX, Assadi M, et al. Updates on 18F-FDG-PET/CT as a clinical tool for tuberculosis evaluation and therapeutic monitoring. Quant Imaging Med Surg. 2019;9:1132-46.

41. Greco S, Girardi E, Masciangelo R, et al. Adenosine deaminase and interferon gamma measurements for the diagnosis of tuberculous pleurisy: a meta-analysis. Int J Tuberc Lung Dis. 2003;7:777-86.

42. Jiang J, Shi HZ, Liang QL, et al. Diagnostic value of interferon-gamma in tuberculous pleurisy: a metaanalysis. Chest. 2007:131:1133-41.

43. World Health Organization, High-priority target product profiles for new tuberculosis diagnostics, 2014. Available at: www.who.int/tb/publications/tpp_report/en/ (accessed October 21, 2020)

44. Sharma JB, Sneha J, Singh UB, et al. Comparative study of laparoscopic abdominopelvic and fallopian tube findings before and after antitubercular therapy in female genital tuberculosis with infertility. I Minim Invasive Gynecol. 2016;23:215-2.

45. Sharma SK, Kohli M, Chaubey J, et al. Evaluation of Xpert MTB/RIF assay performance in diagnosing extrapulmonary tuberculosis among adults in a tertiary care centre in India. Eur Respir J. 2014;44:1090-3.

46. Mahajan N, Naidu P, Kaur SD. Insight into the diagnosis and management of subclinical genital tuberculosis in women with infertility. J Hum Reprod Sci. 2016:9:135-4.

47. Ravikanth R, Kamalasekar K, Patel N. Extensive primary male genital tuberculosis. J Hum Reprod Sci. 2019;12:258-61. 